\title{
Prognostic value of coronary computed tomography (CT) angiography
}

\author{
Stephan Achenbach
}

Address: Department of Cardiology, University of Erlangen, Ulmenweg 18,91054 Erlangen, Germany

Email: stephan.achenbach@uk-erlangen.de

FI000 Medicine Reports 2009, I:6 (doi: 10.3410/MI-6)

The electronic version of this article is the complete one and can be found at: http://FI000.com/Reports/Medicine/content/I/6

\begin{abstract}
Coronary computed tomography angiography (CTA) allows increasingly reliable visualization of the coronary arteries. Over the past two years, several relevant scientific studies on the clinical utility and prognostic value of CT angiography have been published, and this review will provide a summary of the currently available data.
\end{abstract}

\section{Introduction and context}

Coronary computed tomography (CT) angiography is increasingly being used as a tool to visualize the coronary artery lumen and to identify coronary artery stenosis. A recent scientific statement from the American Heart Association [1] and a number of expert consensus documents suggest CT angiography could rule out the need for invasive coronary angiography and may help identify patients in whom invasive coronary angiography can be safely avoided, especially in clinical settings where the likelihood of coronary artery stenosis is intermediate and when testing for ischemia is equivocal $[2,3]$. In addition, it has been shown that contrast-enhanced coronary CT angiography, provided that the image quality is adequate, allows the identification and, to a certain degree, the characterization of not only calcified but also non-calcified coronary atherosclerotic plaque. The predictive power of coronary calcium, with regard to both future cardiovascular events and overall mortality, has been demonstrated in several trials and is undisputed [4], however, the lack of prognostic data has been considered a substantial shortcoming for coronary CT angiography. Recently, important data bearing on the prognostic value of coronary CT angiography have become available. It is important to distinguish three clinical scenarios, which are outlined below.

\section{Recent advances \\ Does a CT angiogram negative for stenosis allow the safe avoidance of invasive angiography in symptomatic patients?}

Gilard et al. [5] studied 200 patients who were scheduled for invasive angiography either because of chest pain and a non-contributory stress test or because of a positive stress test in the absence of symptoms by 16-slice CT. In 18 patients, calcifications were too pronounced to allow the assessment of the coronary arteries for stenosis, and in 41 patients CT did not allow stenoses to be ruled out. In 141 individuals however, CT ruled out significant coronary stenoses and invasive angiography was not performed. Over a mean period of 15 months' follow-up of the initial study, no patients died and only one patient experienced a coronary event (myocardial infarction 19 months after CT imaging). The event rate of $0.7 \%$ per year is similar to that after a normal invasive coronary angiogram in the same clinical setting $(0.6 \%)[6]$, the authors therefore conclude that it is safe to avoid invasive angiography in patients with a negative coronary CT angiogram. Similar results on a smaller scale and with somewhat less well-defined patient inclusion criteria have been reported by Lesser et al. [7] and Gaemperli et al. [8]. 
In another noteworthy study, Danciu et al. [9] analyzed the outcome of 426 patients who were symptomatic and had a positive (intermediate-risk) single photon emission CT (SPECT) scan. In all patients, a 64-slice coronary computed tomography angiography (CTA) was incorporated as the next step of clinical management; this allowed coronary artery stenoses to be ruled out or demonstrated coronary occlusion not requiring revascularization in a total of 343 patients, who subsequently underwent medical management instead of invasive angiography. Over a mean follow-up period of 15 months, only six invasive angiograms were performed in the 343 patients initially referred for medical treatment based on a 'negative' CT scan, and only one of these six angiograms resulted in revascularization. No patients died. Again, the authors conclude that a negative coronary CT angiogram identifies patients in whom invasive angiography can be safely avoided.

Finally, in a very recent study that included data from more than 6.5 million patients, Min et al. [10] demonstrated that the downstream costs of patients undergoing coronary CT angiography as a test to assess previously unknown coronary artery disease was $26 \%$ lower than that of similar patients who underwent nuclear myocardial perfusion scans.

The use of CT angiography also seems attractive in the setting of acute chest pain. Many patients with acute chest pain with initial suspicion of an acute coronary syndrome turn out not to have any coronary artery disease. Therefore CT angiography might be a very attractive rapid imaging test to identify individuals who do not have coronary artery lesions in the setting of chest pain, with the assumption that such individuals may then be rapidly discharged. While several trials have investigated the accuracy of CT angiography in identifying coronary stenoses in the setting of acute chest pain $[11,12]$, only one small trial has followed patients with chest pain who were discharged without any further testing after CT angiography had been used to rule out coronary artery stenoses [13]. Out of 58 patients, CT angiography ruled out significant coronary stenosis in 35 patients, and over a 15-month follow-up period, only one late revascularization and no cardiac death or myocardial infarction occurred. Of course, much larger studies are needed to validate the prognostic value of coronary CTA in this important clinical setting.

\section{Is the presence of coronary plaque, and not only stenosis, predictive of future cardiovascular events in symptomatic patients?}

Since many acute cardiovascular events are caused by the erosion or rupture of non-obstructive coronary atherosclerotic lesions, and CT angiography has the potential to identify such lesions, it is an interesting and important question whether the presence of plaque and not only of significant luminal stenosis - is predictive for future cardiovascular events. Recently, Min et al. [14] published a single-centre cohort study of 1127 patients, $\geq 45$ years old with chest symptoms, who were studied by contrast-enhanced 64-slice coronary CT angiography and followed for all-cause mortality over a mean period of 15 months. The authors demonstrate that the following were significantly predictive of allcause mortality: the presence of any stenosis with a diameter reduction $\geq 70 \%$, the presence of stenoses in the left main coronary artery, and also the presence of plaque in at least five coronary artery segments, whether obstructive or non-obstructive. These initial studies indicate that plaque detected by CT may be of prognostic relevance. However, it is important to note that very small amounts of plaque were not predictive of mortality in this study (which had a relatively short follow-up period).

\section{Is the presence of coronary plaque predictive of future cardiovascular events in asymptomatic individuals?}

Because of the lower overall event rates, predicting acute coronary syndromes in asymptomatic individuals is more difficult than in symptomatic patients. Coronary calcium is predictive for future events even in unselected population samples [15], but this has not yet been shown for coronary CT angiography. In fact, a recent trial of 1000 middle-aged asymptomatic Korean individuals (with a mean age of 50 years) was not able to identify any prognostic value of coronary CT angiography over a 17-month follow-up period [16]. Of the study participants, 22\% had detectable coronary atherosclerotic plaque, but only 15 events occurred. One patient required hospitalization for unstable angina and 14 individuals underwent revascularization (all but one as a result of and within 90 days of the CT examination). No deaths occurred. Therefore, this study in low-risk individuals was not able to demonstrate a prognostic benefit of coronary CT angiography.

\section{Implications for clinical practice}

The ability to detect not only coronary stenoses but also non-obstructive coronary atherosclerotic plaque in a non-invasive fashion makes CT imaging a potentially interesting tool for risk stratification. The rapid technological evolution of CT makes it difficult to obtain longterm data, but several trials concerning the prognostic value of CT angiography have become available and provide some guidance. There is evidence that even in symptomatic patients and in the setting of intermediaterisk stress tests, a CT angiogram that allows coronary arterial stenosis to be ruled out is associated with a very 
good prognosis and permits invasive angiograms to be safely avoided. All the same, in symptomatic patients not selected for pre-test likelihood of coronary artery disease, substantial amounts of non-obstructive plaque may be associated with increased mortality. Asymptomatic individuals, however, do not seem to benefit from CT angiography as a test to assess their prognosis. 'Screening' applications should, therefore, not be encouraged.

\section{Abbreviations}

CT, computed tomography; CTA, computed tomography angiography; SPECT scan, single photon emission CT scan.

\section{Competing interests}

The author has received grant support, consulting fees and lecture honoraria from Siemens, Bracco, GE Healthcare, and Bayer Schering Pharma.

\section{References}

I. Bluemke DA, Achenbach S, Budoff M, Gerber TC, Gersh B, Hillis LD, Hundley WG, Manning WJ, Printz BF, Stuber M, Woodard PK: Noninvasive coronary artery imaging: magnetic resonance angiography and multidetector computed tomography angiography: a scientific statement from the American Heart Association Committee on Cardiovascular Imaging and Intervention of the Council on Cardiovascular Radiology and Intervention, and the Councils on Clinical Cardiology and Cardiovascular Disease in the Young. Circulation 2008, I | 8:586-606.

2. Hendel RC, Patel MR, Kramer CM, Poon M, Hendel RC, Carr JC, Gerstad NA, Gillam LD, Hodgson JM, Kim RJ, Kramer CM, Lesser JR, Martin ET, Messer JV, Redberg RF, Rubin GD, Rumsfeld JS, Taylor AJ, Weigold WG, Woodard PK, Brindis RG, Hendel RC, Douglas PS, Peterson ED, Wolk MJ, Allen JM, Patel MR: ACCF/ACR/SCCT/ SCMR/ASNC/NASCI/SCAI/SIR 2006 appropriateness criteria for cardiac computed tomography and cardiac magnetic resonance imaging: a report of the American College of Cardiology Foundation Quality Strategic Directions Committee Appropriateness Criteria Working Group, American College of Radiology, Society of Cardiovascular Computed Tomography, Society for Cardiovascular Magnetic Resonance, American Society of Nuclear Cardiology, North American Society for Cardiac Imaging, Society for Cardiovascular Angiography and Interventions, and Society of Interventional Radiology. J Am Coll Cardiol 2006, 48:I475-97.

3. Schroeder S, Achenbach S, Bengel F, Burgstahler C, Cademartiri F, de Feyter P, George R, Kaufmann P, Kopp AF, Knuuti J, Ropers D, Schuijf J, Tops LF, Bax J]: Cardiac computed tomography: indications, applications, limitations, and training requirements: report of a Writing Group deployed by the Working Group Nuclear Cardiology and Cardiac CT of the European Society of Cardiology and the European Council of Nuclear Cardiology. Eur Heart J 2008, 29:53I-56.

4. Budoff MJ, Achenbach S, Blumenthal RS, Carr JJ, Goldin JG, Greenland P, Guerci AD, Lima JA, Rader DJ, Rubin GD, Shaw LJ, Wiegers SE; American Heart Association Committee on Cardiovascular Imaging and Intervention; American Heart Association Council on Cardiovascular Radiology and Intervention; American Heart Association Committee on Cardiac Imaging Council on Clinical Cardiology: Assessment of coronary artery disease by cardiac computed tomography: a scientific statement from the American Heart Association Committee on Cardiovascular Imaging and Intervention, Council on Cardiovascular Radiology and
Intervention, and Committee on Cardiac Imaging, Council on Clinical Cardiology. Circulation 2006, I I4:I76I-9I.

5. Gilard M, Le Gal G, Cornily JC, Vinsonneau U, Joret C, Pennec PY, Mansourati J, Boschat J: Midterm prognosis of patients with suspected coronary artery disease and normal multislice computed tomography findings. a prospective management outcome study. Arch Intern Med 2007, I65:I686-89.

6. Lichtlen PR, Bargheer M, Wenzlaff $P$ : Long-term prognosis of patients with angina-like chest pain and normal coronary angiography findings. J Am Coll cardiol 1995, 25:1013-18.

7. Lesser JR, Flygenring B, Knickelbine T, Hara H, Henry J, Kalil A, Pelak K, Lindberg J, Pelzel J, Schwarzt RS: Clinical ultility of coronary CT angiography: coronary stenosis detection and prognosis in ambulatory patients. Catheter Cardiovasc Interv 2007, 69:64-72.

8. Gaemperli O, Valenta I, Schepis T, Husmann L, Scheffel H, Desboiles L, Leschka S, Alkadhi H, Kaufmann PA: Coronary 64-slice CT angiography predicts outcome in patients with known or suspected coronary artery disease. Eur Radiol 2007, I 8: I | 62-73.

FI000 Factor 3.0 Recommended

Evaluated by Stephan Achenbach 26 Mar 2008

9. Danciu SC, Herrera CJ, Stecy PJ, Carell E, Saltiel F, Hines JL: Usefulness of multislice computed tomographic coronary angiography to identify patients with abnormal myocardial perfusion stress in whom diagnostic catheteriation may be safely avoided. Am J Cardiol 2007, 100:1605-08.

10. Min JK, Kang N, Shaw LJ, Devereux RB, Robinson M, Lin F, Legorreta $A P$, Gilmore A: Costs and clinical outcomes after coronary multidetector CT angiography in patients without known coronary artery disease: comparison to myocardial perfusion SPECT. Radiology 2008, 249:62-70.

II. Hoffmann U, Nagurney JT, Moselewski F, Pena A, Ferencik M, Chae CU, Cury RC, Butler J, Abbara S, Brown DF, Manini A, Nichols JH, Achenbach S, Brady TJ: Coronary multidetector computed tomography in the assessment of patients with acute chest pain. Circulation 2006, I |4:225 I-60.

12. Meijboom WB, Mollet NR, Van Mieghem CA, Weustink AC, Pugliese $F$, van Pelt N, Cademartiri F, Vourvouri E, de Jaegere P, Krestin GP, de Feyter PJ: 64-Slice computed tomography coronary engiography in patients with non-ST elevation acute coronary syndrome. Heart 2007, 93:1386-92.

13. Rubinshtein R, Halon DA, Gaspar T, Jaffe R, Karkabi B, Flugelman MY, Kogan A, Shapira R, Peled N, Lewis BS: Usefulness of 64-slice cardiac computed tomographic angiography for diagnosing acute coronary syndromes and predicting clinical outcome in emergency department patients with chest pain of uncertain origin. Circulation 2007, I I 5:1762-8.

14. Min JK, Shaw LJ, Devereix RB, Okin PM, Weinsaft JW, Russo DJ, Lippolis NJ, Berman DS, Callister TQ: Prognostic value of multidetector coronary computed tomographic angiography for prediction of all-cause mortality. J Am Coll Cardiol 2007, 50: I |6I-I I70.

FI000 Factor 3.2 Recommended

Evaluated by Christopher Kramer 28 Nov 2007, Stephan Achenbach 21 Dec 2007

15. Detrano R, Guerci AD, Carr JJ, Bild DE, Burke G, Folson AR, Liu K, Shea S, Szloko M, Bluemke DA, O'Leary DH, Tracy R, Watson K, Wong ND, Kronmal RA: Coronary calcium as a predictor of coronary events in four racial or ethnic groups. $N$ Engl J Med 2008, 358:1336-45

FI000 Factor 3.0 Recommended

Evaluated by Daniel Berman with Arik Wolak 29 Apr 2008

16. Choi EK, Choi SI, Rivera JJ, Nasir K, Chang SA, Chun EJ, Kim HK, Choi DJ, Blumenthal RS, Chang HJ: Coronary computed tomography angiography as a screening tool for the detection of occult coronary artery disease in asymptomatic individuals. J Am Coll Cardiol 2008, 52:357-65. 